Article

\title{
Bounded rationality effect on firm's choices on R\&D investments: A model for decision-making effectiveness analysis
}

\author{
Marcos Ferasso ${ }^{1 *}$ and Eloisio Andrey Bergamaschi ${ }^{2}$ \\ ${ }^{1}$ Community University of Chapeco Region, Brazil; admmarcosferasso@gmail.com \\ 2 SESI Innovation Institute, Brazil; eloand@gmail.com \\ * Correspondence: admmarcosferasso@gmail.com
}

Received: 23 January 2020; Accepted: 21 February 2020; Published: 23 February 2020.

\begin{abstract}
How effective is the taken R\&D investment decision, considering the effect of bounded rationality? Guided by this question, it is explored the decision-making process at the group level within the firm. A mathematical model for determining the effectiveness of decision-making based on the group's experience is proposed. By considering subjective and objective factors, the Decisionmaking Effectiveness Index - Dei, model was created. To prove theoretical hypotheses and testing the model, a randomly generated dataset was built consisting of 4,000 individuals that were grouped representing 500 hypothetical firms. After performing the simulation, both hypotheses were confirmed, and the model was validated. The main theoretical findings evidenced that the project's success will depend on decision-makers' cognitive capacity. As a contribution for practitioners, this research highlighted the importance of considering group experience in a self-analysis effectiveness index. Procedures are proposed for comparing the firm effectiveness index with competitors for improving firm decision-making performance.
\end{abstract}

Keywords: Bounded rationality; decision-making process; R\&D projects; R\&D investments; cognitive capacity; decision-making effectiveness index.

JEL codes: M1; D7; D81; D91; O32.

\section{Introduction}

The major, if not the main, asset responsible for a firm's survival is innovation. One of the most common ways to achieve an innovation is through investments in Research and Development (R\&D). However, firms do not always select the best (or sub-optimal) option for their investments decisions, which results in an accumulation of transaction costs due mistakes. There are firms that are worth much of their intuition and accumulated experience during the decision-making process, although subjective criteria do not always provide the desired results.

At the basis of decision-making process, there is bounded rationality, a concept in which central idea is the limitation of rationality when an individual considers options in decision-making process (Simon, 1957, 1970). Since the firm's decisions arise from a group of decision-makers: Who determine firm's future? Which decision to take? What will be the best option? Based on the classical assumption 'no one knows everything', unexpected effects (Taleb, 2010) must be considered on decision-making process. So, a question remains: How to distinguish how effective is the taken decision, considering the effect of bounded rationality?

The way decisions are taken was a subject of several researches in interdisciplinary studies involving; Economics, Mathematical Modeling, Sociology, Social Psychology, Cognitive Psychology, 
and Organizational Theory. Some examples on these themes can be found in researches like the individual level of decisions (Camerer, 1998; Georgiou, 2006; Georgiou, 2008; Schoemaker, \& Russo, 1993) and those that deals on organizational theories approach of decision-making (Courtney, 2001; Foss, 2003; Nelson, 2008). Very few researches addressed specifically the decision-making process at group level (DiTomaso, Smith, Farris, \& Cordero, 2007; White, Dittrich, \& Lang, 1980), or the influence of culture on decision-making (Becker, 2004).

A particular firm commonly has decision-makers who engage in the evaluation of alternatives by selecting those projects through evaluating the options in a given time. Thus, decision-makers are considering, in a joint way, the selection of the 'best choices' (not the optimal choices) due to the limitation of available resources, limited options, brief time to evaluate and to decide, as well as the limitation from cognitive ability of each of these decision-makers. The authors argue in this research paper that the collective decision-making on a particular project is a common practice in organizations as a strategy to overcome the cognitive limitations of alternatives evaluation and selection. Such collective decisions must be related in an attempt to reduce the bias to which bounded rationality can lead a given decision-maker. Therefore, the question the authors address with this research paper is: how to measure the firm's decision-making process effectiveness?

Mostly studies already published have considered groups' decision-making processes with several moderators, elements or contexts, like escalation of commitment and sensitivity and the use of programmable decisions and statistical approaches (Curseu, Schruijer, \& Fodor, 2016; Parker, 1980). The cognitive aspects addressed were emotional intelligence in decision-making process, the problem to a leader in involving a team in a major decision, and the magnitude of impact and quality of decision process output regarding rationality of strategic decision-making process (Hess, \& Bacigalupo, 2011; Nooraie, 2008; Schwarber, 2005).

Although there are several researches that highlighted the importance of decision-making process, at an individual or group level, there is some attempts in proposing mathematical models to measure the decision-making process. The model proposed by Herrera-Viedma, Chiclana, Herrera and Alonso (2007) was conceived regarding experts' preferences. The integration of multiplicative relation as a preference in multipurpose decision-making problems is the approach of Chiclana, Herrera and Herrera-Viedma (2001). The available mathematical/theoretical models stress several relations, moderators and influence variables, and the most adherent to this research is the model proposed by Beiner, Drobetz, Schmid and Zimmermann (2004), where it is found that firms are trying to increase their board of directors' effectiveness by selecting criteria like composition, independence and size. However, a model that can determine specifically the effectiveness of decision-making based on decision-making experience at group level remains.

This research aims to fill this research gap by proposing a mathematical model for determining the effectiveness of decision-making process at group level, considering the modeling of subjective and objective factors that will result in an index, i.e., the Decision-making effectiveness index - Dei. This index is a result that can be compared with other firms or competitor firms, to better address a firm's strategy in improving their decision-making accuracy.

As main contributions, this research paper addresses the following:

- the proposition of a research agenda for decision-making process at a group level, considering the identification of constitutive factors in a model that can measure the decision-making effectiveness at a group level. It is addressed at the group level mainly because organizations' strategic level is constituted by a board of directors (Beiner et al., 2004) - which represents a group of decision makers;

- an index that can be accompanied by the firm as a tool for increasing their decision-making effectiveness on R\&D investments by the proposition of a mathematical model which can determine an effectiveness index of decision-making of a given firm by comparison with other firms' scores;

- to bring more attention to the fact that, in practice, many firms are more prone to decide critical subjects; not being constituted by only one director but in a collective way mainly due to the constitution of their board of directors (Beiner et al., 2004); 
- to practitioners, this mathematical model will represent the decision-making effectiveness accuracy; as a possibility to accompany the effectiveness index of their board of directors by storing a continuum of indexes and analyzing how this index evolves;

- theoretically, this paper will contribute to understand the effect of firm's cognitive ability on the effectiveness of choice for investments in R\&D and a model to measure the impact of this decisionmaking process on firm's effectiveness will be proposed.

This paper is structured, beyond this introduction, by a theoretical review section where concepts are discussed, and hypotheses presented, a section which is devoted to the explanation and where the mathematical model is presented followed by a section where the model is tested with randomly generated data, the next section presents the results and the discussion and then it is presented the conclusion and consulted references.

\section{Literature review}

\subsection{Decision-making process in firm context}

In theory, all firms should be equal, this does not occur also due to the firm's cognitive capacity, according to Neoclassical Economic approach. Firms have different experiences and different agents (entrepreneurs) and with different experiences. The variability of the firm's function, i.e., the way in which the firm combines their variables, is responsible for interfirm difference. These differences are also responsible for the infeasibility of concept of production function with maximum profit and the balance concept.

According to Cohen and Cyert (1965), behavioral theory of the firm applies to firms whose decisions are not completely determined by the market due to the freedom enjoyed by them in developing their decision-making strategies and rules that become part of decision-making system within these firms. Thus, the behavioral theory of the firm has as approach the structure of the internal decision-making process of the firm.

To Herbert Simon is credited the main contribution to the Theory of the Firm. Simon considered resumption of decision-making within organizations from the perspective of firm's behavior (Löbler, 2005). The decision-making model of bounded rationality is related to the cognitive aspects that are considered in decision-making due to the limitations of human rationality. This model is opposed to the rationality of economic man. So, confronted by the limitations of time and knowledge, the decision maker cannot find the optimal decision, but only the most suitable in relation to available options in a certain period (Simon, 1945).

In this study, firm's concept of Coase (1937) is used as background with focus on entrepreneur and his decisions. The firm is an economic agent that solves the problem of the economic agent named consumer. The firm, to be firm, depends on the decisions of the entrepreneur, and these decisions are directly related to entrepreneur's bounded rationality.

In decision-making process, it is assumed that better decide who possess the better cognitive ability, based in previous successful decisions, taken thanks to individual experiences and a higher information quantity and quality. The problem is the amount of information to be processed in a given period of time, added to this the fact that firms usually decide on investment projects in R\&D collectively by their board of directors. These factors make the decision-making process not as simple and fast. Besides, each firm has its specific form of decision.

Regarding to collective decisions, the board of directors is still not straightly aligned with better results (which can be considered as the best investment projects in R\&D in this research). Although Lipton and Lorsch (1992) and Jensen (1993) identified that a board of directors is composed by 7 to 8 , this size may vary. This variance is due to the intuitiveness determination of director's board size by companies, in the basis that larger boards tend to be more effective for fulfilling the management capacity. The authors are, in an indirect way, referring to the interval of cognitive limitation of an individual and the limits where the board is not in a way to effectively contribute to the decisionmaking process. Beiner et al (2004), identified that there is no relationship between board size and 
lower valuations, which means that at individual level the bounded rationality plays a significant role by limiting the cognitive rationality, but maximum number to constitute a board is not clarified.

Descartes (1977) described the way he dealt with his limited rationality, stating that as he could not examine all options due to the complexity and human limitation, then decided to break the options and then review them in their entirety. This fragmentation is known as Cartesian method. The failure to consider the evaluation of all alternatives added to the cognitive impairment of the decision maker and the pressures to decide faster leads to an evaluation of some options within the limits of rationality. Thus, the rationality limitation will determine how right will be the choice.

From Simon (1945), the theory of decision-making process has expanded the quantitative approach to involve more complex and contingent aspects. The rational model of decision-making, for example, considers the construction of options that optimal levels and risks are calculated, and the best alternative is selected.

Löbler (2005) reports that the rational model is characterized as a process of building quantitative options where, after calculations, the optimal levels for risks are found by simply choosing the alternative that brings more results. Thus, the best decision at any given time would be that one that brings the best cost/benefit from mathematical calculations results. The problem in these calculations is that this rational model does not consider the subjective factors behind the decision-making process. Graham et al. (as cited in Freitas, Macadar, \& Moscarola, 1996), had already highlighted the need to understand cultural differences in decision-making processes.

Löbler (2005) states that the main contribution of Simon was the approach of individual decisionmaking process of the firm, because until then, theorists only regarded the market as a whole. The group decision-making and effects of cognitive diversity was the research of Olson, Bao and Parayitam (2007). This study, conducted with two hundred fifty-two Chinese executives from different firms, revealed that cognitive diversity has a negative relationship with the commitment and the quality of the decision.

West (2007) affirmed the importance of examining cognition at groups' level. The collective cognition is mediated between individual cognition and the firm's actions and performance. The study evidenced that two structural features of collective cognition (differentiation and integration) are strongly related to the firm's performance.

Hammond, Keeney and Raiffa (2006) argue that bad decisions can lead the way by which they were made: if the alternatives were not clearly defined, the correct information will not be selected if the costs/benefits were not properly measured. Sometimes, the fault may lie in the decision-making process as well as the mind of decision maker: the way the human mind works can sabotage the decision-makers' choices.

The research conducted by Zanela (1999), performed in Brazil, France and in the USA, revealed that in relation to decision-making style, in general, the respondents proved to be more rational and objective. Related to the speed for taking decision, the author also reports that the decision-making style refers that decisions are taken in a fast way.

Regarding the group behavior during decision-making process, Simon (1945) underlined that when considering more than one individual in decision-making, the decisions of others will be included among the conditions under which the individual (alone) should consider in relation to their own decision. Each individual need to know what the actions of others will be, what is an extremely important fact during the collective decision-making process.

Another aspect to address in decision-making process is its effectiveness. There are attempts to simplify the decision-making processes, most of them related to the establishment of more rational ways of deciding to achieve effective decisions. Van De and Delbecq (1971) addressed the effectiveness in decision-making process. The said authors focused in groups discussions versus individual silent efforts in a group setting. The authors concluded that the best results came from a rational three-stage process for addressing problems. This process begins with a committee divided tasks, followed by interacting discussions and by choosing the best option by vote. In other research conducted by Dean Jr. and Sharfman (1996) was identified that a rational decision-making process is required to achieve 
decision success. In their longitudinal study, it was determined that the procedural rationality and the political behavior influences on decision success. Thus, an organized process of decision-making can increase the outcomes effectiveness.

The decision-makers are affected by objective and subjective factors before and during the process of evaluating alternatives and that these factors can influence the group of decision makers and imply in the effectiveness of decision-making and firm's choice.

\subsection{Cognitive capacity on decision-making process of a firm}

In Cognitive Psychology, Neisser first treated cognition in 1967 and was defined as a process that captures, transforms, reduces, prepares, stores, retrieves, and uses external stimuli (Best, as cited in Boff, 2000; Löbler, 2005). Cognition was treated by Boff (2000) as a process and mental state of understanding information in a knowledge worker concept.

Simon (1957) and Newell and Simon (1972), found that cognitive capacity of decision-makers is limited to knowledge and attitudes, i.e. decision-makers reduce, simplify and approximate the choices closer to reality, becoming the principle of bounded rationality (Freitas, 1992). Simon (1970) underlined that the main concern of organization theory is related to boundaries between rational and irrational aspects of an individual's social behavior. Thus, Management theory is a theory founded on intentional and bounded rationality of human behavior.

Hernandez and Ortega (2019) also addressed the impact of bounded rationality in decisionmaking process. The authors identified that the context information is critical in decision-making processes that involve large amounts of resources. In this view, organizations take 'sub-optimal' decisions due to their limited ability to process information. Thus, one issue to be solved by organizations is the knowledge content quality (Jahmani, Fadiya, Abubakar, \& Elrehail, 2018). This feature is also highlighted by Negulescu and Doval (2014) when studying the quality of decisions. Despite socio-economical fields or regions, it was identified that the decision effectiveness depends on the organization's effectiveness conceptual model. It was also identified that the quality of taken decisions is influenced by the quantity of available information. Moreover, the decision makers usually take advices from their team members, which reinforce the role of the group in the decision-making process.

Thus, every administrative decision is relative. This is because managers tend to take rational decisions due to various informational and cognitive limitations (Simon, 1945). This is due the chosen alternative is always the most appropriate, not representing the 'optimum alternative' (March, \& Simon, 1966).

Löbler (2005) reports that the incremental model has as its starting point the limited cognitive capacities of decision makers, which reduces the radius of action and costs of information collection and processing. The decision maker only considers some alternatives, only covering the most important consequences. This model received critics regarding the neglection of basic innovations by focusing on the short term. This fact is explained by the high probability of making a mistake resulted by a wrong decision, which stimulates an inertia in decision-making, influencing decision-makers to not exceed their limits and being more conservatives in their decisions.

Abubakar, Elrehail, Alatailat and Elçi (2019) considered the intuitive and rational decisionmaking styles as moderating effect in organizational performance. The intuitive style is considered as a decision maker's feeling and a result of a holistic analysis, and its path is difficult to describe. The rational style is a structured process of assessment and selecting alternatives, mostly based in predetermined decision criteria that are undertaken by the decision maker.

Gonzalez, Fakhari and Busemeyer (2017) studied dynamic decision-making and complex decision processes. It was noticed a trend in facilitating the process of decision-making by reducing complexity of dynamic decision-making through decomplicating the tasks. One key factor in dynamic decisionmaking processes is the human being, due to individual characteristics such as: experience, knowledge and adaptation ability. 
Another individual perspective of decision-making is taken by Kotlar and Sieger (2018), when addressing the individual-level entrepreneurial behavior of family/nonfamily managers in family firms. The authors found that family managers possess greater factors if compared with entrepreneurial behavior of nonfamily managers.

By considering cognitive psychological theories to understand the decision-making process, it is assumed that the human being is an 'encoder information system'. Thus, the decision-making process would be considered as the result of perception, mental models, emotions, attitudes and memory of past experiences (Löbler, 2005). Whether cognitive capacity of a decision maker has a significant impact on collective decision-making process, once cognition precedes the evaluation of alternatives to choose from, how to quantify these indicators? How to measure the effectiveness of decision-making that resulted on a given choice?

Taking as starting point the fact that cognitive capacity precedes the decision of a particular decision maker, this capacity re-feed the 'reflection-evaluation-decision' cycle and evolves the decision maker's experience in the form of a spiral, like the spiral of knowledge (Nonaka, \& Takeuchi, 1995).

The decision-making process experience of a decision maker is also characterized as an essential element in relation to cognitive capacity. Zanela, Freitas and Becker (1998) state that the decisionmaking process experience comprises a set of skills acquired over an individual's life, including age, education, work experience, administrative responsibilities, which form the 'decision-making experience' of the individual. This 'decision-making process experience' results in a more or less experienced individual.

Chi and Fan (1997) concluded that human intuitive errors and biases in investment management under uncertainty tend to result in large losses when the project requires a long gestation and development of higher costs. So, it is two factors that are responsible for forcing the cognitive capacity of the firm: the time and the complexity of the decision to be taken.

The limitation for processing information leads to errors and biases, since the human mind has developed a heuristic principle to reduce the complex duty of judging, in situations where this capacity is exceeded (Chi, \& Fan, 1997). Based on experimental results with human cognition involved with project management, the authors found that subjective judgments of decision-makers are subject to severe errors and biases that resemble the adoption of sub-optimal decisions rules.

Some attempts to increase the effectiveness of decision-making process include the use of Information \& Technology (IT) tools. Gürkut and Nat (2018) stated that decision-making can be facilitated by the use of information systems in the Education sector. The authors underlined that the effectiveness of organizational decision-making process can be achieved by higher education institutions when using the Student Information Systems. Thus, IT tools can aid decision makers in the complex role of evaluating alternatives.

Researches of strategy's cognitive processes have focused on the limits of rationality in strategic planning process. There is a positive relationship between cognitive capacity and the dominant logic of the firm (Phelan, 2002).

Due to the fact that a firm is composed by groups of individuals, e.g. board of directors, who usually decide on investments in R\&D, it is argued that cognition of each decision maker is part of a larger set that would be called in this research 'cognitive capacity of the firm'. This capability can be understood mathematically as a simple arithmetic mean of all individual internal cognitive capacities of the firm, greatly depending on time constraints and the complexity of the decision to be taken.

\subsection{Bounded rationality of a firm}

Rationality is addressed by Simon (1945) and is understood as the selection of preferred behavioral alternatives in relation to a particular value system, by which behavioral consequences can be evaluated. Simon (1945) stated that the accuracy of a managerial decision is relative, and it will be correct if the means to achieve stated purposes would be properly selected. The rational manager deals with the selection of these effective resources. The author reported that administrative decisions are directly related to aspects of rational choice. 
Choices evaluation involve the selection of an alternative among several others, and decisions are influenced in each momentary behavior in which the choices are made. Once it is considered a series of decisions as a strategy, whether a possible strategy is chosen and implemented, certain consequences will appear. The rational decision maker's task is to select the strategy that will result in desired consequences (Simon, 1945).

In this way, strategy process goes through three phases: 1) to list all alternative strategies, 2) to determine all consequences of each strategy, and 3) to establish a comparative evaluation of the set of all consequences. It is somewhat obvious that it is impossible for an individual to know all alternatives and consequences, and this impossibility is an important principle in relation to the current behavior (Simon, 1970). So, the organization can commit to a particular action pathway. Once started, the organization may prefer to continue with this action pathway rather than abandon what had already been started.

Simon (1957) has stated that it is not possible to determine the efficiency of an organization through the identification of all factors involved in this process. Thus, to simplify the method, the author recommended using an organization's member, by questioning about the qualitative and quantitative limits of his own limitation. These limits include a) limits on performance skills, and b) limits on the ability to make correct decisions. Simon underlined that an important fact to be considered is that the limits of rationality are variable limits, and awareness of these limits can, per se, change these limits.

Thus, it is affirmed that the competence of a decision maker is a function ratio of the amount of processed information (knowledge) divided by time. In theory, the decision maker who processes more information in less time, is supposed to be the most competent decision maker.

Tiwana, Wang, Keil and Ahluwalia (2007) addressed bounded rationality in management decisions in their study. The research was conducted with eighty-eight firms' managers. The authors noticed that decision-making process was more successful when the quantifiable benefits are easy to evaluate and represent low monetary values; but unsuccessful when the benefits are more complex to evaluate and represent higher values. The authors argued that the bounded rationality of decision makers facing high uncertainty makes these perceive less quantifiable benefits related to IT projects.

Instead of the presented limitations, if decision maker would process all information in a brief period of time, if focused on the evaluation of the most appropriate information, this will reduce the processing time and increase competencies of decision maker. The authors considered that there is another limiting factor in processing all the said information: the cognitive capacity of decision maker.

\subsection{Hypotheses presentation}

As presented in the introduction section, this study intends to contribute to decision sciences by a proposition of a mathematical modeling to measure the decision-making effectiveness. The ideas were based on statements of firm's concept and the entrepreneur as decision maker, the bounded rationality, the objective and subjective factors that influence the alternatives evaluation processes, the collective way by which decisions are taken in more complex subjects (as R\&D investments), and the cognitive capacity of the firm.

The authors believe that, in literature of decision sciences, the subject of measuring the decisionmaking effectiveness is still not well addressed, mainly if it is considered the subjective and objective factors by which a group of individuals decide, and by considering a set of factors that determine individual/group experience in decision-making processes in a mathematical modeling.

Thus, based on the above-mentioned assumptions, the hypotheses of this study are presented: H1a - A group of decision-makers decide more effectively rather than an individual decision-maker $H 1 b$ - The better decision-making experiences a group have, the better is the decision-making effectiveness of such group

Considering the presented hypotheses, the mathematical model for measuring the firm's decision effectiveness is built, as presented and discussed in the following section. 


\section{Measuring decision effectiveness of a firm}

Due decisions on investments in $R \& D$ are not a routine or a simple duty, normally these decisions are deliberated collectively. How to know if decisions being taken are the right decisions? How to know if the firm is heading for the right destination?

Theoretically, it is considered that the best decision-makers are those who have the highest cognitive ability. But, how to determine this cognitive ability? From this question, it was elaborated a set of enabling alternatives in the cognitive process of decision makers to be considered in order to reduce the effect of bounded rationality in decision-making processes on R\&D investments.

The transaction costs resulting from a wrong choice in investments is twofold: besides the fact of having the wrong choice and have lost the investment, it is also being lost the opportunity to be one step ahead on the market than competitors.

It is believed that a decision-maker can be guided by a purely objectivist bias to concentrate their decisions on new investments in R\&D based on the best results obtained in the past, i.e., the decision maker's procedures for evaluating alternatives are path dependents.

Thus, the firm faces the risk of disregarding possibilities of disruptive innovations (Christensen, 2012) that could take it to market leadership in their market niche. The bounded rationality of a decision-maker is the main factor in selecting possible alternatives for R\&D investment.

Since decision-makers do not have all available knowledge and apply this knowledge in their decision-making process, an error index in the decision will always be present. As previously postulated by Simon in his studies, the cognitive capacity of decision-maker will always be less than the 'total knowledge'. By total knowledge, the authors refer to all cumulative knowledge to be considered in all decision-making processes of all existing organizations. Once manager has limitations in its rationality, a group of decision makers (e.g., the board of directors of a given company) tend, in each of its individuals, evaluate alternatives that may have not being considered by other decision maker. In theory, the authors underline that a group of decision makers can reduce the bounded rationality of a given and particular decision-maker. As above-mentioned, the firm will never have the 'total knowledge', but the knowledge of a single decision-maker will always be less than the knowledge of a group of decision makers.

To reduce the effect of Simon's bounded rationality, several scientific studies have been drafted proposing quantitative and qualitative techniques to be used in the determination of what would be the best option of choice on the part of decision makers. Thus, the proposed model seeks to quantify the named 'cognitive ability of the firm' from a mathematical model where this capability can be evaluated prior to the start of decision-making process - the evaluation of alternatives.

To measure decision-making process effectiveness by a ratio of firm's decision-making process on R\&D investments, three main factors are considered: a) the arithmetic mean of decision-making experience of a group of decision makers on R\&D investments; $b$ ) the number of wrong choices of projects, i.e., projects that the firm chose to invest in the past but who have not attained the predicted objectives; and c) the total number of projects in which the firm decided to invest.

The authors believe that by relating these factors, it is possible to obtain the decision-making effectiveness index of the firm throughout their investment decisions in R\&D. This indicator could be used to track firm's performance to decide on their investments in R\&D at a given time, and to compare the decision-making effectiveness of various decision-making groups of the firm, or even self-evaluate in a continuum.

The decision-making experience would be a composition of factors that were relevant to the improvement process of decision-making. The authors underline that these factors are subjective, and the scope is to obtain an indicator of the individuals' decision-making experience that make up the group responsible for choosing investments in $R \& D$ projects.

The selected variables had as main objective to identify the number of decision-making stimuli that a particular individual was exposed throughout his life. Based on this number of stimuli, it is considered that an individual would have greater decision-making experience and, therefore, better conditions to decide on investments in R\&D. The firm's decision-making experience would be 
obtained through the average of the different decision-making experiences of all individuals who are part of the group responsible for investment decisions of firm's R\&D. In this way, the firm's decisionmaking experience may change over time, in that individual's profile who participate in the decisionmaking group is modified, as in exit or entry of new members into this decision-making group.

Basically, and in a continuum, the group of decision-makers - since maintained, tends to become more experienced, which leads to improved decision-making effectiveness of the firm.

The model was built based on two dimensions (subjective and quantitative), two goals questions $\left(P C_{w}\right.$ and $\left.P_{t}\right)$ and a subjective question $(\overline{D e})$. The considered factors to form the decision-making experience were: age, level of education, experience with other cultures, work experience, financial expertise, project management experience, managerial experience and the type of decisions that are sufficient to establish an initial reference to the decision-making experience of a particular group of decision makers.

Age. The age factor was considered due that the life experience gained by the numerous interactions that an individual gets in his day-to-day activities can contribute to his decision-making background. Experience is related to an individual's age, due as interactions with different people, organizations and institutions, these experiences will accumulate over time, i.e., people learn over time and with situations and contexts.

Level of education. The level of education can also assist in the composition of decision-making experience once submitting an individual to various challenges throughout their educational and intellectual growth. And the higher and qualified educational level is, the higher level of decisionmaking interactions the individual will be exposed, which will, thereby, contribute to the formation of decision-making experience. The authors believed that exposure to higher levels of knowledge is a key factor in the formation and intelligence of an individual.

Experience with other cultures. The experience with other cultures allows an individual to learn and understand different viewpoints, broadening their world view and hence increasing the number of variables that were disregarded in the decision-making process. The exposure to diverse cultures may contribute to the decision-making experience in that an individual can view threats, challenges and opportunities in diverse ways, i.e., by means of different cultural filters.

Professional experience. Work experience in the industry in which is being evaluated an investment project contributes to the indicator of decision-making experience once known peculiarities of this industry will contribute to have a larger view of opportunities and threats and an individual will be better able to evaluate the risks involved in the decision.

Financial experience. The financial experience, in this research is interpreted as the experience of an individual regarding investments in the stock market. Operations involving stocks in financial market are recognized for their high associated risk. By participating in investments in financial market, the individual is subjected to numerous stimuli and variables that influence the decision-making process. It is considered that the learning obtained through this process, either by hits or errors, better prepare the individual to deal with subjects involving financial risk. Thus, this experience can contribute significantly improve the process of decision-making ability of an individual.

Experience in projects management. Another factor considered to form the decision-making experience of an individual is the experience in projects management. Being responsible for managing projects, the individual is subjected to numerous stimuli that challenge his decision-making capacity. The main contribution of this factor in the composition of individual's decision-making experience is the practical learning as practitioner. Projects management experience tends to spread the variables considered in decision-making for new projects investments, thus, contributing to the improvement of the decision-making capacity.

Managerial experience. Managerial experience is also considered as a factor to compound the decisionmaking experience. This is considered as the amount of years of experience of an individual, that works in managerial positions. This position, by their own nature, involve decision-priority activities, where the individual is submitted daily to the exercise of decision-making process. It is considered that managerial experience, by developing the duties over years and its consequently changes - due 
to the influences of decision-making stimuli, contributes to the decision-making experience of an individual, which is expected to be significantly higher than that of another person who has not had the same work experience.

Types of decisions taken. The type of decision-making factor is also related to managerial experience. It is considered that tactical and strategic decisions involve greater risk and, therefore, a larger number of variables to be analyzed, exposing the decision maker to stimuli that can improve his decisionmaking capacity.

The decision-making experience of each member that makes up the firm's decision-making group is the sum of scores obtained from each element mentioned above, according to the questionnaire presented in Annex 1. The individual decision-making experience can vary from a minimum of 8 points up to 44 points. Although there is a limit on a maximum expected decision-making experience regarding a group, the maximum limit of the decision-making effectiveness index is unknown because is not possible to determine the total number of projects that a firm can start. So, it is assumed that the index is comparable, in academia, to the H index created by Hirsch (2005), where there the minimum index can be predicted, but not the same with the maximum index due that the total citations of a research paper tends to the infinite.

The decision-making effectiveness index is obtained by the ratio among the average of the group's decision-making experience, divided by the number of wrong project choices and total number of projects. This index indicates how effective is being the group's decision-making experience on decision-making investments in R\&D projects. The greater the number of project errors, the lower the index of decision-making effectiveness. However, if the number of wrong projects is low, the denominator will enhance the firm's decision-making experience, thereby increasing the index of decision-making effectiveness.

In considering the non-chosen projects, it is assumed that the non-choice of a project (that may lead to a positive result) is a decision-maker(s) error, and this error lead to the same effect in the mathematical model as a wrong decided project. Thus, it is considered that the total of wrong choices of projects of our model $\left(P C_{w}\right)$ consider the sum of the properly wrong decided projects and the nonchosen projects to be invested.

The authors believed that wrong decisions in $R \& D$ investments can seriously compromise the survival of the firm, because of this, the mistakes in firm's decisions is penalized, as can be seen in the formula. It is considered that errors in project choices, especially in the initial phases of the firm's life cycle, could not compromise the index of decision-making effectiveness, thus seeks to ameliorate the impact of this effect by using the square root in the denominator of the result.

$$
D e i=\frac{\overline{D e}}{\sqrt{\left(\frac{1+P C_{W}}{1+P_{t}}\right)}}
$$

Where:

Dei: Decision-making effectiveness index.

$D e$ : Decision-making experience, maximum mean of 5.5; minimum mean of 1.

$P C_{w}$ : Amount of wrong choices of projects.

$P_{t:}$ Total of decided projects.

Once presented the hypotheses and the mathematical model to measure the decision-making effectiveness of the firm (i.e. the group of decision makers), tests were performed to calibrate the model and prove the effectiveness of the formula.

\subsection{Model testing and results discussion}

The decision-making effectiveness proposed in the previously presented mathematical model was tested through random-number generator using MS Office Excel ${ }^{\circledR}$ program. The steps it was 
selected to perform the model tests were based on a decision-making process approach, according to operational research (Ackoff, 1979). All phases of model testing procedures are described as following.

The first step was to build an Excel ${ }^{\circledR}$ matrix with randomized data regarding three groups of data: 1) Information regarding the characteristics of each individual decision-maker to build a supposed profile (based on Annex 1); 2) Calculation regarding the average of all supposed group members from each individual decision-maker mean; and 3) Randomized data regarding supposed firms' projects data (total decided projects and the number of wrong chosen projects).

The authors defined at individual-level observation the total amount of hypothetic 4,000 individual decision-makers, with different score profiles automatically randomized by Excel ${ }^{\circledR}$ program. They also defined the minimum number of groups (where a group of decision-makers represent one hypothetical firm), to randomly group the individuals within 500 firms. This attempt in determining the maximum number of groups was arbitrated by the authors to saturate the data. The 4,000 individuals were randomly and automatically inserted in each group and assuring that each group of individuals would be formed by different number of individuals.

As null hypothesis, it was determined that 20 firms (4\%) of all groups were formed by only one individual, to compare the firms' score in which were formed by a group of decision-makers. This procedure allowed to test hypothesis H1a stated previously. The maximum and minimum total of individuals of a group represent the board of directors' size that, according to Lipton and Lorsch (1992), and Jensen (1993), can vary from 7 to 8 . This interval is assumed due the size of directors' board of a company is not large (Beiner et al., 2004). Thus, it is considered this assumption for determining the average number of each board of directors.

The next step in testing the model was the definition of the total number of projects a firm may have, and the total number of wrong choices on projects a firm may undertake. Regarding the total number of projects and the number of chosen projects that a firm may undertake, it is found in Lieb's (1998) mathematical model the fundamentals for defining an adequate number of projects to receive R\&D investments. Lieb's (1998) model lead to the conclusion that the optimal R\&D projects a firm may invest is a one-third ratio. Thus, it is considered this definition in our mathematical model by assuming, logically and theoretically, that firm's wrong choices on R\&D projects tend to be two-third of all their R\&D projects.

Although there is a limitation on the group decision experience $(D e)$, the total number of projects tends to the infinite, and the number of wrong projects will be always (and logically) smaller than the total number of projects. At a worst supposed situation, when the total number of projects and wrong projects are equals, the decision-making effectiveness index (Dei) remains as the group decision experience $(D e)$.

One of the main issues in the model testing was the definition of the total number of R\&D projects a firm may have. This is due the total number/failure statistics are hidden by firms, mainly due to strategical concerns, what turned this data search very difficult and time consuming. The authors performed searches on scientific databases and on open search tools, and no result was found to satisfy the data needed. Then, the authors performed searches based on information that are publicly available, such as reports from governments and public funding agencies. It is found on a report of OECD that, in one year, 4,080 R\&D projects presented by 659 German firms received funds (Fier, Aschloff, \& Löhlein, 2006), which represents an average ratio of 6 funded R\&D projects per firm.

In defining the limits of average funded R\&D projects, the authors assumed as minimum and obvious funded $R \& D$ projects the number 1 , and the maximum number 12 . This is according to the precepts of interval delimitation from a mean (Ross, 2017). The authors applied Lieb's (1998) principles on optimal R\&D projects investments ratio of one-third. Thus, to get the total number of projects, it must be multiplicated by three, which results in a maximum of 36 (12 maximum number of funded projects $x 3$, the supposed total number of projects in Lieb's model) R\&D projects a firm may have as average ratio.

The authors underline that project number delimitation is an intent to build a model testing more adherent to the supposed real numbers for both (total number of projects and total number of invested 
projects) which, in turn, will determine the total of abandoned/wrong/unsuccessful/unchosen projects. As stated previously, although the total number of projects tends to the infinite (and, thus, the same for $\mathrm{Dei}$ ), the authors performed these model tests in order to prove a more realistic data that can reflect firms' realities. It is suggested future model tests to perform calculations considering real data from firms, which represents a new contribution to the field.

After conducting the model tests, it is presented in Figure 1 the results of each 500 firms Dei index, which means that the results of each individual firm may be compared with each one of the other 499 .

Figure 1. Disposition of individual results of firms regarding their Dei index

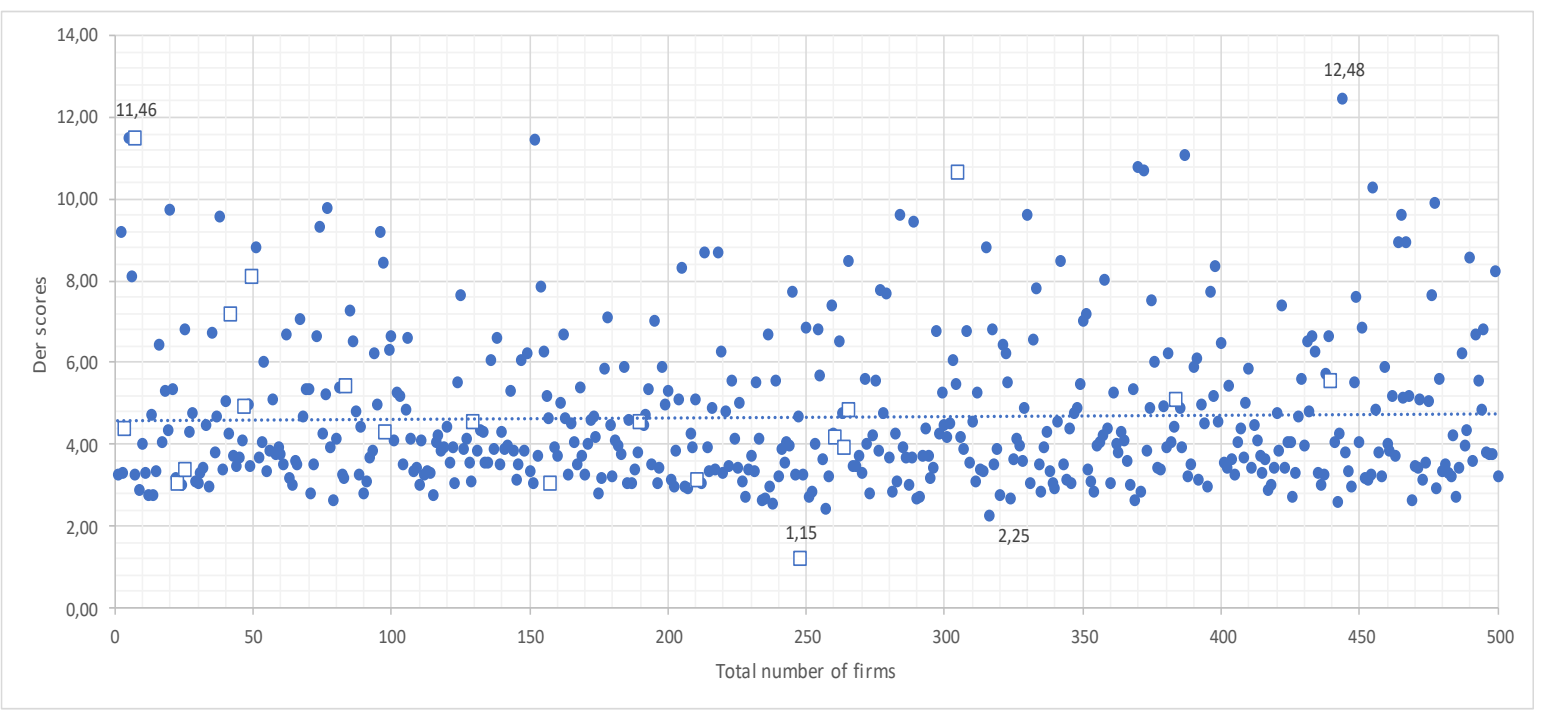

Source: primary data.

It is presented in the dispersion graph all 500 cases, representing each calculated Dei scores. The cases composed by only one decision-maker are detached by the squares on the graph. All other cases (dots) represent firms which are composed by a board of decision-makers. The pointed line on the graph shows the scores' mean (4.66).

After performing the simulation, it was identified the worst case represented by a firm with an individual decision-maker, whose Dei score is 1.15. The best individual decision-maker's score is the Dei of 11.46. Although mostly simulated cases are near the mean, the authors stress that the same occurred to the individual decision-maker's cases. Only nine cases formed by one decision-maker are higher than the mean. The authors obtained three cases formed by board of decision-makers that showed equal or higher Dei scores than the maximum score of a firm composed by one decision-maker. These results confirm hypothesis $H_{1 a}$.

Regarding hypothesis $H_{1 b}$, the best Dei score of a firm composed by one decision-maker (shown on Table 1 ) is represented by the score 5.0 of case 8 , as shown on the graph (Dei=11.46). The authors ranked the top-ten best Dei scores (Table 1 ) and it was found just one firm composed by one decisionmaker among them. This represents that the best decisions were taken by firms composed by a board of decision-makers, evidencing that group decision-making experience mean is influenced by each individual experience. In considering these assumptions, they confirm the hypothesis $H_{1 b}$.

By ranking all decision-making experiences $(D e)$ of all 4,000 individuals, the authors discovered that the top-ten best De scores (Table 2) resulted from seven cases formed by one decision-maker. However, even if individual decision-makers have the best individual decision-making experience $(D e)$, this was not sufficient to obtain a better result in Dei score - the best score of 5.0 of case 8 . Once it was used randomly generated data, this hypothesis needs a confirmation with real data and real procedures for the establishment of board of directors: a board of directors is not formed without criteria, but with a careful consideration of individual's experience. 
Table 1. Top-ten best and worst individual Dei scores

\begin{tabular}{ccc|ccc}
\hline \multicolumn{5}{c}{ Firms decision-making scores classified according to Dei score } \\
\hline \multicolumn{3}{c|}{ Top-ten Dei best scores } & \multicolumn{3}{c}{ Top-ten Dei worst scores } \\
\hline $\begin{array}{c}\text { Cases } \\
\text { (firm number) }\end{array}$ & De score & Dei score & $\begin{array}{c}\text { Cases } \\
\text { (firm number) }\end{array}$ & De score & Dei score \\
\hline 444 & 3.07 & 12.48 & $248^{*}$ & 1.00 & 1.15 \\
5 & 3.38 & 11.48 & 316 & 2.25 & 2.25 \\
152 & 3.45 & 11.46 & 257 & 2.33 & 2.40 \\
$8^{*}$ & 5.00 & 11.46 & 238 & 2.20 & 2.54 \\
387 & 3.60 & 11.10 & 442 & 2.50 & 2.61 \\
370 & 4.50 & 10.79 & 369 & 2.50 & 2.61 \\
372 & 3.22 & 10.69 & 234 & 2.25 & 2.62 \\
305 & 3.00 & 10.61 & 79 & 2.64 & 2.64 \\
455 & 3.25 & 10.28 & 469 & 2.64 & 2.64 \\
477 & 2.75 & 9.92 & 290 & 2.69 & 2.69 \\
\hline
\end{tabular}

* Firm composed by one decision-maker.

Source: primary data.

Table 2. Top-ten best and worst individual De scores

\begin{tabular}{ccc|ccc}
\hline \multicolumn{5}{c}{ Firms decision-making scores classified according to De score } \\
\hline \multicolumn{3}{c|}{ Top-ten De best scores } & \multicolumn{3}{c}{ Top-ten De worst scores } \\
\hline $\begin{array}{c}\text { Cases } \\
\text { (firm number) }\end{array}$ & De score & Dei score & $\begin{array}{c}\text { Cases } \\
\text { (firm number) }\end{array}$ & De score & Dei score \\
\hline $84^{*}$ & 5.00 & 5.40 & $248^{*}$ & 1.00 & 1.15 \\
$8^{*}$ & 5.00 & 11.46 & 296 & 1.88 & 3.42 \\
$190^{*}$ & 4.50 & 4.50 & 238 & 2.20 & 2.54 \\
18 & 4.50 & 5.32 & 316 & 2.25 & 2.25 \\
370 & 4.50 & 10.79 & 234 & 2.25 & 2.62 \\
449 & 4.17 & 7.61 & 402 & 2.25 & 3.44 \\
$261^{*}$ & 4.00 & 4.14 & 257 & 2.33 & 2.40 \\
$4^{*}$ & 4.00 & 4.35 & 232 & 2.35 & 5.51 \\
$47^{*}$ & 4.00 & 4.90 & 235 & 2.42 & 2.69 \\
$385^{*}$ & 4.00 & 4.90 & 280 & 2.42 & 3.67 \\
\hline
\end{tabular}

* Firm composed by one decision-maker.

Source: primary data.

On the other hand, the top-ten worst decision-making experience $(D e)$, shown in Table 2, is composed by nine board of decision-makers. The hypothesis $H_{1 b}$ could be confirmed if analyzed the worst cases, where Dei score of the group is related with the group experience $(D e)$. In analyzing the total Dei mean (Figure 1), it is perceived that most firms formed by board of decision-makers with high Dei score are over the mean, if compared with the firms composed by just one decision-maker. Thus, if it is considered the data in general - which means considering all the plotted data on the graph, hypothesis $H_{1 b}$ is confirmed.

The authors believe that the effect of generating random data to form the decision-making experience $(D e)$ of all individuals influenced the composition of the De group mean. This is because in a firm composed by only one decision-maker, all the decision-making experience represent the whole experience of only one individual. On the other hand, a board of decision-makers is formed by a firm that considers each individual decision-making experience, which attenuate the mean effect of the mathematical model. This tends to lead to an increased group mean effect due the decision-makers are carefully chosen to form the respective board. If the real data could be aligned with this assumption, it confirms this theoretical assumption and confirming hypothesis $H_{1 b}$. 
Even it is faced a great disparity between the De and Dei scores, the main objective of this research paper was proved by testing and approving that the proposed mathematical model is functional. The authors recommend to researchers in decision-making and operational research fields of study to perform simulations with real data, or even by comparing a single firm path, by comparing their own performance with own previous results.

\section{Final considerations}

This paper aimed, in an objective way, to stress the effect of bounded rationality in the decision to invest in R\&D projects and proposed a mathematical model to measure the decision-making effectiveness index of a given firm. Thus, it was necessary to identify the subjective and objective elements that directly influence the formation of cognitive capacity of each decision-maker, and therefore the formation of cognitive capacity of the firm. The authors believed that due to this, a project's success will largely depend on decision-maker's capacity that a given firm dispose.

The frequent concern during model elaboration and testing was the establishment of objective parameters to identify the firm's decision-making effectiveness, i.e. their cognitive capacity, regarding the decisions for R\&D projects investment.

In the Dei model, it was identified the cognitive elements that influence the decisions on R\&D investments. The main novelty of this paper is the consideration of a group experience in a mathematical model. Dei model was idealized to measure the effectiveness index of decision-making choices of the firm, i.e., their board of decision-makers. The authors believed that this instrument is an objective parameter for self-analysis of a firm, with regard to their own evolution in terms of their decision-making choices, or even by comparing with competitors or other firms in the same/other industries.

As limitations, this research used random data using Excel ${ }^{\circ}$ program, and the groups (board of directors) of all 500 firms were randomly formed. As stated in the previous section, the impossibility to access the real data from firms prevented a more accurate information, especially regarding the assumption that 'a group decides better than in individual' (which lead to the refusion of hypothesis $H_{1 b) \text {. }}$

As suggestions for future researches, the authors would recommend the application of this model with real firm's data and testing a concurrent hypothesis if there are an inverse correlation between the greater group experience, the lesser errors in projects decisions.

Although the authors assumed that the factors that form the mathematical model proposed in this research, they stress that those were considered as the main influenced factors in a decision for R\&D project investments. The authors encourage researchers to include other factors that may influence a group of decision-making, such as: situational factors, contingencial factors, path factor, and the inclusion/exclusion of individuals during the firm's path. The mentioned factors may influence the results, even whether the group may show a high De score.

Supplementary Materials: The full dataset used in model testing is available upon request to the corresponding author.

Author Contributions: Conceptualization, E.A. Bergamaschi and M. Ferasso; methodology, M. Ferasso; software, M. Ferasso; validation, M. Ferasso; formal analysis, E.A. Bergamaschi and M. Ferasso; investigation, M. Ferasso; resources, M. Ferasso; data curation, M. Ferasso; writing-original draft preparation, E.A. Bergamaschi and M. Ferasso; writing-review and editing, M. Ferasso; visualization, M. Ferasso; All authors have read and agreed to the published version of the manuscript.

Funding: This research received no external funding.

Acknowledgments: Marcos Ferasso would like to thank Afonso Ricardo Paloma Vicente for his helpful comments regarding data calculations and experiments, Sandro Nystrom Lozekam for revising the text, and to CNPq for funding through a scholarship. The authors thank to the two anonymous reviewers and the Editor Adam Zaremba for their insightful revisions and comments that improved this research paper. 
Conflicts of Interest: The authors declare no conflict of interest.

\section{Appendix A - Questionnaire to identify the decision-making experience}

Age

Decision-maker age

( ) 1. Up to 20 years old

( ) 2. From 20 to 30 years old

( ) 3. From 30 to 40 years old

( ) 4. From 40 to 50 years old

( ) 5. From 50 to 60 years old

( ) 6. More than 60 years old

\section{Level of education}

Formal level of education of decision-maker:

( ) 1. College degree

( ) 2. Incomplete undergraduate degree

( ) 3. Undergraduate degree

( ) 4. Specialization degree

( ) 5. Master's degree

( ) 6. Doctorate degree

\section{Experiences with other cultures}

Living in different cultures, different worldviews.

No experience \begin{tabular}{|l|l|l|l|l|}
\hline 1 & 2 & 3 & 4 & 5 \\
\cline { 2 - 6 }
\end{tabular}

\section{Professional experience}

Working time of decision-maker on industry focus of analysis:

\begin{tabular}{|c|c|c|}
\hline ) & 1. & Up to 2 years \\
\hline & 2. & From 2 to 5 years \\
\hline & 3. & From 5 to 10 years \\
\hline & 4. & From 10 to 15 years \\
\hline & 5. & From 15 to 20 years \\
\hline & 6 & More than 20 years \\
\hline
\end{tabular}

\section{Financial experience}

Time experience in investments in the stock market. Consider monitoring with frequency of at least 1 time per week and business volume of at least USD 10,000.

\begin{tabular}{|c|c|c|}
\hline ) & 1. & Up to 2 years \\
\hline ) & 2. & From 2 to 5 years \\
\hline ) & 3. & From 5 to 10 years \\
\hline ) & 4. & From 10 to 15 years \\
\hline ) & 5. & From 15 to 20 years \\
\hline ) & 6. & More than 20 years \\
\hline
\end{tabular}

\section{Experience in projects management}

Number of projects which you acted as project manager:

\begin{tabular}{|c|c|c|}
\hline ) & 1. & Up to 3 projects \\
\hline ) & 2. & From 3 to 5 projects \\
\hline ) & 3. & From 5 to 15 projects \\
\hline ) & 4. & From 15 to 25 projects \\
\hline ) & 5. & From 25 to 40 projects \\
\hline
\end{tabular}


( ) 6. More than 40 projects

\section{Managerial experience}

Activity years as manager or executive:

\begin{tabular}{|c|c|c|}
\hline ) & 1. & Up to 2 years \\
\hline ) & 2. & From 2 to 5 years \\
\hline ) & 3. & From 5 to 10 years \\
\hline ) & 4. & From 10 to 15 years \\
\hline ) & 5. & From 15 to 20 years \\
\hline 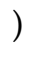 & 6. & More than 20 years \\
\hline
\end{tabular}

\section{Type of decisions taken}

Type of decisions taken with major frequency - operational, routine or tactical and strategic, with impact in long term:

\begin{tabular}{|l|l|}
\hline 1 & Operational decisions \\
\hline 2 & Tactical decisions \\
\hline 3 & Strategic decisions \\
\hline
\end{tabular}

\section{References}

Abubakar, A. M., Elrehail, H., Alatailat, M. A., \& Elçi, A. (2019). Knowledge management, decision-making style and organizational performance. Journal of Innovation $\mathcal{E}$ Knowledge, 4(2), 104-114. https://doi.org/10.1016/j.jik.2017.07.003

Ackoff, R. (1979). The Future of Operational Research is Past. The Journal of the Operational Research Society, 30(2), 93-104. https://doi.org/10.1057/jors.1979.22

Bade, S. (2005). Nash equilibrium in games with incomplete preferences. Economic Theory, 26(2), 309-332. https://doi.org/10.1007/s00199-004-0541-1

Barney, J.B., \& Hesterly, W. (2004). Economia das organizações: entendendo a relação entre as organizações e a análise econômica. In S. Clegg; C. Hardy \& D. Nord (Orgs.), Handbook de estudos organizacionais (3rd ed.). (pp. 131-179). São Paulo, SP: Atlas.

Becker, J.L. (2004). Nota técnica: a tomada de decisão nas organizações. In S. Clegg; C. Hardy \& D. Nord (Orgs.), Handbook de estudos organizacionais (3rd ed.). (pp. 311-312). São Paulo, SP: Atlas.

Beiner, S., Drobetz, W., Schmid, F., \& Zimmermann, H. (2004). Is board size an independent corporate governance mechanism? Kyklos, 57(3), 327-356. https://doi.org/10.1111/j.0023-5962.2004.00257.x

Boff, L.H. (2000). Processo cognitivo de trabalho de conhecimento: um estudo exploratório sobre o uso da informação no ambiente de análise de investimentos. (Unpublished doctoral dissertation). Universidade Federal do Rio Grande do Sul, Porto Alegre, Brazil.

Camerer, C. (1998). Bounded rationality in individual decision making. Experimental Economics, 1(2), 163-183. https://doi.org/10.1023/A:1009944326196

Chi, T., \& Fan, D. (1997). Cognitive limitations and investment "myopia". Decision Sciences, 28(1), $27-57$. https://doi.org/10.1111/j.1540-5915.1997.tb01301.x

Chiclana, F., Herrera, F., \& Herrera-Viedma, E. (2001). Integrating multiplicative preference relations in a multipurpose decision-making model based on fuzzy preference relations. Fuzzy Sets and Systems, 122(2), 277-291. https://doi.org/10.1016/S0165-0114(00)00004-X

Christensen, C.M. (2012). Disruptive Innovation. In M. Soegaard \& R. F. Dam (Eds.). Encyclopedia of HumanComputer Interaction. Aarhus, Denmark: The Interaction-Design.org Foundation. Retrieved from http://www.interaction-design.org/encyclopedia/disruptive_innovation.html

Clark, N. (1985). The political economy of science E technology. Oxford: Blackwell.

Coase, R.H. (1937). The nature of the firm. Economica, 4(16), 386-405. https://doi.org/10.1111/j.14680335.1937.tb00002.x

Cohen, K.J. \& Cyert, R.M. (1965). A Behavioral Theory of the Firm. Englewood Cliffs, NJ: Prentice Hall.

Courtney, J.F. (2001). Decision making and knowledge management in inquiring organizations: toward a new decision-making paradigm for DSS. Decision Support Systems, 31(1), 17-38. 
Curseu, P.L., Schruijer, S.G., \& Fodor, O. C. (2016). Decision rules, escalation of commitment and sensitivity to framing in group decision-making: An experimental investigation. Management Decision, 54(7), 1649-1668. https://doi.org/10.1108/MD-06-2015-0253

Dean Jr, J. W., \& Sharfman, M. P. (1996). Does decision process matter? A study of strategic decision-making effectiveness. Academy of Management Journal, 39(2), 368-392. https://doi.org/10.5465/256784

Descartes, R. (1977). O discurso do método. Mem Martins: Europa-América.

DiTomaso, N., Post, C., Smith, D.R., Farris, G.F., \& Cordero, R. (2007). Effects of structural position on allocation and evaluation decisions for scientists and engineers in industrial R\&D. Administrative Science Quarterly, 52(2), 175-207. https://doi.org/10.2189/asqu.52.2.175

Even, A., \& Shankaranarayanan, G. (2007). Utility-driven assessment of data quality. ACM SIGMIS Database, 38(2), 75-93. https://doi.org/10.1145/1240616.1240623

Fier, A., Aschhoff, B., \& Löhlein, H. (2006). Behavioural additionality of public RED funding in Germany. Government R\&D funding and company behaviour. Measuring behavioural additionality, Paris: OECD Publishing.

Foss, N.J. (2003). Bounded rationality in the economics of organization: "Much cited and little used". Journal of Economic Psychology, 24(2), 245-264. https://doi.org/10.1016/S0167-4870(02)00206-4

Freitas, H. de. (1992). L'aide a la decision pour l'utilisateur final: ou et comment intervenir ? Papier de Recherche. Grenoble: Université Pierre Mendès-France Grenoble 2, n. 1.

Freitas, H., Macadar, M.A. \& Moscarola, J. (1996). Na busca de um método quanti-qualitativo para estudar a percepção do tomador de decisão. Proccedings of The $20^{\text {th }}$ Encontro Anual da ANPAD, Rio de Janeiro.

Freitas, H., Zanela, A. and Becker, J.L. (1997). A concepção e validação de um conjunto de instrumentos quantiqualitativos para estudar o processo decisório segundo as culturas nacionais e os níveis de experiência decisória. Proceedings of The $21^{\text {th }}$ Encontro Anual da ANPAD, Rio de Janeiro.

Georgiou, I. (2006). Managerial effectiveness from a system theoretical point of view. Systemic Practice and Action Research, 19(5), 441-459. https://doi.org/10.1007/s11213-006-9035-3

Georgiou, I. (2008). Making decisions in the absence of clear facts. European Journal of Operational Research, 185(1), 299-321. https://doi.org/10.1016/j.ejor.2006.12.038

Gonzalez, C., Fakhari, P., \& Busemeyer, J. (2017). Dynamic decision making: Learning processes and new research directions. Human factors, 59(5), 713-721. https://doi.org/10.1177/0018720817710347

Gürkut, C., \& Nat, M. (2017). Important factors affecting student information system quality and satisfaction. EURASIA Journal of Mathematics, Science and Technology Education, 3/2018, 14, 923-932. https://doi.org/10.12973/ejmste/81147

Hammond, J.S., Keeney, R.L., \& Raiffa, H. (2006). The hidden traps in decision making. Harvard Business Review, 84(1), 118.

Herrera-Viedma, E., Chiclana, F., Herrera, F., \& Alonso, S. (2007). Group decision-making model with incomplete fuzzy preference relations based on additive consistency. IEEE Transactions on Systems, Man, and Cybernetics, Part B (Cybernetics), 37(1), 176-189. https://doi.org/10.1109/TSMCB.2006.875872

Hess, J.D., \& Bacigalupo, A.C. (2011). Enhancing decisions and decision-making processes through the application of emotional intelligence skills. Management Decision, 49(5), $710-721$. https://doi.org/10.1108/00251741111130805

Hirsch, J.E. (2005). An index to quantify an individual's scientific research output. Proceedings of the National Academy of Sciences of the United States of America, 102(46), 16569-16572. https://doi.org/10.1073/pnas.0507655102

Jahmani, K., Fadiya, S. O., Abubakar, A. M., \& Elrehail, H. (2018). Knowledge content quality, perceived usefulness, KMS use for sharing and retrieval. VINE Journal of Information and Knowledge Management Systems, 48(4), 470-490. https://doi.org/10.1108/VJIKMS-08-2017-0054

Jensen, M.C. (1993). The modern industrial revolution, exit, and the failure of internal control systems. Journal of Finance, 48(3), 831-880. https://doi.org/10.1111/j.1540-6261.1993.tb04022.x

Kotlar, J., \& Sieger, P. (2019). Bounded rationality and bounded reliability: A study of nonfamily managers' entrepreneurial behavior in family firms. Entrepreneurship theory and practice, 43(2), 251-273. https://doi.org/10.1177/1042258718796085

Lieb, E.B. (1998). How many R\&D projects to develop? IEEE Transactions on Engineering Management, 45(1), $73-77$. https://doi.org/10.1109/17.658663 
Lipton, M., \& Lorsch, J.W. (1992). A modest proposal for improved corporate governance. The Business Lawyer, 48(1), 59-77.

Löbler, M.L. (2005). Processamento da informação: uma avaliação dos diferentes níveis de conhecimento no processo de decisão. (Unpublished doctoral dissertation). Universidade Federal do Rio Grande do Sul, Porto Alegre, Brazil.

March, J.G., \& Simon, H. (1966). Teoria das organizações. Rio de Janeiro: FGV.

Negulescu, O., \& Doval, E. (2014). The quality of decision making process related to organizations' effectiveness. Procedia Economics and Finance, 15, 858-863. https://doi.org/10.1016/S2212-5671(14)00548-6

Nelson, R.R. (2008). Bounded rationality, cognitive maps, and trial and error learning. Journal of Economic Behavior $\mathcal{E}$ Organization, 67(1), 78-89. https://doi.org/10.1016/j.jebo.2007.06.002

Newell, A., \& Simon, H.A. (1972). Human problem solving. (Vol. 104, No. 9). Englewood Cliffs, NJ: Prentice-Hall.

Nonaka, I., \& Takeuchi, H. (1995). The knowledge-creating company: How Japanese companies create the dynamics of innovation. Oxford university press.

Nooraie, M. (2008). Decision magnitude of impact and strategic decision-making process output. Management Decision, 46(4), pp.640-655. https://doi.org/10.1108/00251740810865102

Olson, B.J., Bao, Y., \& Parayitam, S. (2007). Strategic decision making within Chinese firms: The effects of cognitive diversity and trust on decision outcomes. Journal of World Business, 42(1), 35-46. https://doi.org/10.1016/j.jwb.2006.11.007

Parker, L.D. (1980). Evaluating group decision-making in the corporate environment. Management Decision, 18(1), 35-44. https://doi.org/10.1108/eb001232

Penrose, E. (1995). The Theory of the Growth of the Firm. New York, NY: Oxford University Press.

Phelan, S.E. (2002). Cognitive capacity as competitive advantage: a simulation test. Simulation Modelling Practice and Theory, 10(5), 455-471. https://doi.org/10.1016/S1569-190X(02)00121-1

Ramchandra, V., \& Srikant, S.R.E.E.D.H.A.R. (2006). Data quality for enterprise risk management. Business Intelligence Journal, 11(2), 18.

Ross, S.M. (2017). Introductory statistics (4th ed.). London: Elsevier.

Schoemaker, P.J., \& Russo, J.E. (1993). A pyramid of decision approaches. California Management Review, 36(1), 931. https://doi.org/10.2307/41165732

Schumpeter, J.A. (1942). Capitalismo, socialismo e democracia. Rio de Janeiro: Fundo de Cultura.

Schwarber, P.D. (2005). Leaders and the decision-making process. Management Decision, 43(7/8), $1086-1092$. https://doi.org/10.1108/00251740510610099

Simon, H.A. (1945). Administrative Behavior. Nova York: Free Press.

Simon, H.A. (1957). Administrative behavior: a study of decision making processes in administrative organizations (2nd ed.). New York: McMillan.

Simon, H.A. (1970). Comportamento administrativo: estudo dos processos decisórios nas organizações administrativas. Rio de Janeiro, RJ: FGV.

Simon, H.A. (2013). Administrative behavior: a study of decision-making processes in administrative organizations (4th ed.). New York, NY: The Free Press.

Taleb, N.N. (2010). The black swan: the impact of the highly improbable (2nd ed.). New York, NY: Random House.

Tiwana, A., Wang, J., Keil, M., \& Ahluwalia, P. (2007). The bounded rationality bias in managerial valuation of real options: Theory and evidence from IT projects. Decision Sciences, 38(1), 157-181. https://doi.org/10.1111/j.1540-5915.2007.00152.x

Van De, A., \& Delbecq, A. L. (1971). Nominal versus interacting group processes for committee decision-making effectiveness. Academy of Management Journal, 14(2), 203-212. https://doi.org/10.5465/255307

Wang, R.Y., \& Strong, D.M. (1996). Beyond accuracy: What data quality means to data consumers. Journal of Management Information Systems, 12(4), 5-33. https://doi.org/10.1080/07421222.1996.11518099

West, G.P. (2007). Collective cognition: When entrepreneurial teams, not individuals, make decisions. Entrepreneurship Theory and Practice, 31(1), 77-102. https://doi.org/10.1111/j.1540-6520.2007.00164.x

White, S.E., Dittrich, J.E., \& Lang, J.R. (1980). The effects of group decision-making process and problem situation complexity on implementation attempts. Administrative Science Quarterly, 25, 428-440. https://doi.org/10.2307/2392261

Winter, S.G. (1993). On Coase, Competence, and the Corporation. In O.E. Williamson \& S.G. Winter (Eds.). The nature of the Firm: Origins, Evolution, and Development. Oxford: Oxford University Press. 
Zanela, A. I. C., Freitas, H., \& Becker, J. L. (1998). A influência da cultura e da experiência decisória sobre a percepcão do processo decisório individual: um estudo comparativo inicial entre Brasil, França e EUA. Proceedings of the $22^{\text {th }}$ Encontro Anual da ANPAD, Foz do Iguaçu.

Zanela, A.I. da C. 1999. A influência da cultura nacional e da experiência decisória sobre a percepção do processo decisório individual: um estudo comparativo entre Brasil, França e Estados Unidos. (Unpublished master thesis). Universidade Federal do Rio Grande do Sul, Porto Alegre, Brazil. 